\title{
TRIBOLOGICAL BEHAVIOUR OF POLYMERS IN TERMS OF PLASMA TREATMENT: A BRIEF REVIEW
}

\author{
HAYDER AL-MALIKI *1 AND GÁBOR KALÁCSKA ${ }^{1}$ \\ ${ }^{1}$ Faculty of Mechanical Engineering, Mechanical Engineering PhD School, Szent István University, Páter \\ Károly utca 1, H-2100 Gödölló, HUNGARY
}

\begin{abstract}
A review to enrich the literature concerning the effect of various plasmas on the tribological behaviour of polymers and monitor the developments of plasma for the modification of polymer surfaces over recent decades using up-to-date data. A comparative study of plasmas was conducted to identify the most useful and efficient ones which facilitate optimal improvements with regard to the characterizations of polymer surfaces and tribological properties. The studies included in this review strongly suggest that (besides Plasma-Immersion Ion Implantation, PIII) atmospheric plasmas (dielectric barrier discharges, DBD) are an effective technique in terms of modifying the characterizations of polymer surfaces thereby enhancing the tribological behaviour of polymers under different operating conditions that extends the operating life of elements within the machine.
\end{abstract}

Keywords: polymer, plasma treatment, surface characterization, tribology

\section{Introduction}

The term tribology originates from two Greek words, namely $\tau \rho \iota \beta \omega$ (tribo), a verb which means "I rub"; and the suffix -logy which is derived from $\lambda \omega \gamma \iota \alpha$ (logia) which can be translated as "study of" or "knowledge of". This word was introduced by the British scientists Bowden, Tabor [1] and Jost in 1964 [2]. Luke Mitchell, a professor of lubrication, observed the problems caused by increasing the level of friction exerted on machines [3]. Tribology is the science which studies the principles and applications of friction, wear and lubrication [4]. Friction and wear are widespread phenomena in our daily lives. Processes that result in friction occur when moving surfaces are in contact with each other [5]. Friction is a consequence of two main non-interacting components (adhesion and deformation) and can be considered as an approach for all materials including polymers. Polymers are nonpolar materials that exhibit unique tribological behaviour, and some of them possess good selflubrication characteristics, examples of which are stated in $[6,7]$. The rapid development of industry was accompanied by the urgent need to decrease the size of equipment which in turn leads to a higher degree of friction and enhanced rates of wear to be exerted on the elements of machines. This prompted the evolution of several surfacemodification techniques, in particular for polymers, to diminish the disadvantages of friction and wear. The alteration of surface properties such as hydrophilicity, chemical composition and roughness lead to inevitable changes

\footnotetext{
*Correspondence: haidrlatif@gmail.com
}

in tribological behaviour which provided an opportunity for researchers to govern such behaviour with regard to polymers. Therefore, specific techniques have been developed over the last few years to modify the surfaces of polymers to improve frictional behaviour and adhesive bonding performance. A lot of chemical and physical techniques have been developed to treat the surfaces of polymers. Chemical techniques are the processes which deal with wet or chemical reactions on surfaces, for instance, wet etching, grafting, acid-induced oxidation and plasma polymerization. Physical techniques deal with the modification of physical surfaces such as corona discharge, ion or electron beams, photon beams, plasma discharge and oxidizing flames [8].

Experimentally, the chemical treatments of polymer surfaces exhibit some disadvantages such as localized corrosion and environmental pollution. In contrast, physical treatments have been adapted recently to modify the surface of polymers [9]. One of the most effective techniques to modify the surfaces of polymers are plasmas which facilitate changes in the properties of polymer surfaces by several processes, for instance, cleaning, ablation, crosslinking and surface chemical functionalization [10].

Recently, plasma surface treatment was referred to as the most accepted method of modifying the surface of polymeric materials due to its remarkable stability concerning the enhancement of surface properties compared to conventional techniques, in particular, atmospheric plasma treatment which has the ability to operate under ambient atmospheric conditions (in terms of temperature 
and humidity) and does not require a vacuum $[9,11]$. The literature often suggests that plasma treatment may improve the hydrophilicity of polymers [12-16], which has also been demonstrated in our previous works [17-19]. Even though plasmas often increase the surface roughness of polymers $[15,20,21]$, some studies have proven that a decrease in surface roughness might occur after shorter treatment times [16,22].

The present study attempts to review the tribological aspects of polymeric materials treated by various plasmas and compared to their pristine surface behaviour by taking into consideration the influence of plasmas on the characteristics of polymer surfaces which vastly governs the tribological behaviour of polymers. Finally, plasma types that may currently be recommended to utilize and reinforce the tribological properties of polymers are highlighted.

\section{Plasma Modification of Plastic Surfaces}

Plasma can be defined as a chemically active media. The composition of plasmas varies depending on the way they are generated and their working power. Plasmas produce either low or very high temperatures and according to the heat they generate they can be termed as cold or thermal plasmas. Thermal plasmas, especially arc plasmas, were widely industrialized by the aeronautic sector in particular. Cold plasma technologies have evolved in the microelectronics industry, but they have a limited use due to their vacuum equipment. There have been many attempts to transpose plasmas to work under atmospheric pressure without the need for a vacuum. The research has led to various sources that are described in [23].

It is known that plasma is the fourth state of matter and it is more or less an ionized gas that constitutes about $99 \%$ of the universe. Plasma consists of electrons, ions and neutrons; these constituents may exist in fundamental or excited states. From a laboratory point of view, plasma is electrically neutral. However, it contains some free charge carriers thus is electrically conductive $[24,25]$. The degree of plasma ionization can range from small values, e.g. $10^{-4}-10^{-6}$ for partially ionized gases to $100 \%$ for fully ionized gases. In a laboratory, two types of plasma can be generated; the first are hightemperature plasmas which are also referred to as fusion plasmas, the second are low-temperature plasmas or gas discharges [26].

\subsection{Classification of plasmas}

Plasmas can be differentiated into several groups depending on the energy supply and amount of energy transferred to them since the properties of a plasma change depending on electronic density or temperature as presented in Fig. 1 [23]. There are two major plasma groups - the first are thermal equilibrium plasmas and the second are those not in thermal equilibrium. Plasmas that consist of

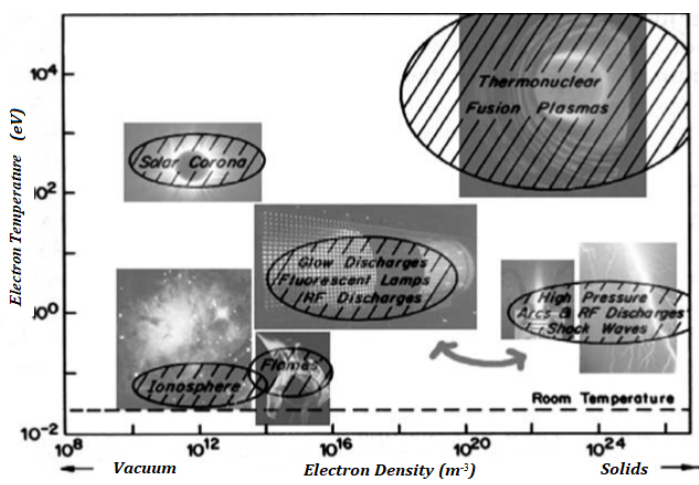

Figure 1: 2D classification of plasmas (electron temperature versus electron density) [28].

particles (electrons, ions and neutral species) of uniform temperature are known as thermal equilibrium plasmas, for instance, stars and fusion plasmas. Usually they are termed as "local thermodynamic equilibrium plasmas" which is abbreviated to LTE. High temperatures typically ranging from $4,000 \mathrm{~K}$ to $20,000 \mathrm{~K}$ are required to obtain thermal equilibrium plasmas. Otherwise, plasmas that are not in thermal equilibrium, abbreviated as non-LTEs, will be formed, for example, interstellar plasma matter [25]. LTE and non-LTE plasmas can be distinguished according to the gas pressure the plasma is subjected to. A high gas pressure is indicative of many collisions in the plasma and it could be argued that just a few collisions occur in the plasma when the gas pressure is low, for example, dielectric-barrier discharge and atmospheric pressure glow discharge plasmas. More details about types, sources and applications of plasmas can be found in [27].

\subsection{Influence of plasmas on the surface char- acteristics of polymers}

Different types of plasma treatments have exhibited potential changes in the physical and chemical surface characteristics of polymers. The variation in wettability is a fundamental parameter that controls adhesion, lubrication and/or interactions with molecules. The formation of polar groups at the surface following plasma treatments, such as carbonyl, carboxyl and hydroxyl groups, enhances the surface energy. The enhancement of wettability following plasma treatment can be a combined effect of surface functionalization and an increase in surface roughness. When surface grafting occurs relatively quickly, an increase in surface roughness has mainly been observed following longer treatment times [21]. Depending on the selection of adequate parameters, different types of plasma treatment are used for either enhancing as well as diminishing adhesion or surface hardness.

Experimentally, Tóth et al. [29] observed a significant improvement in the surface hardness of ultra-high molecular weight polyethylene (UHMWPE) following nitrogen plasma ion implantation (NPII). The hydrogen plasma 


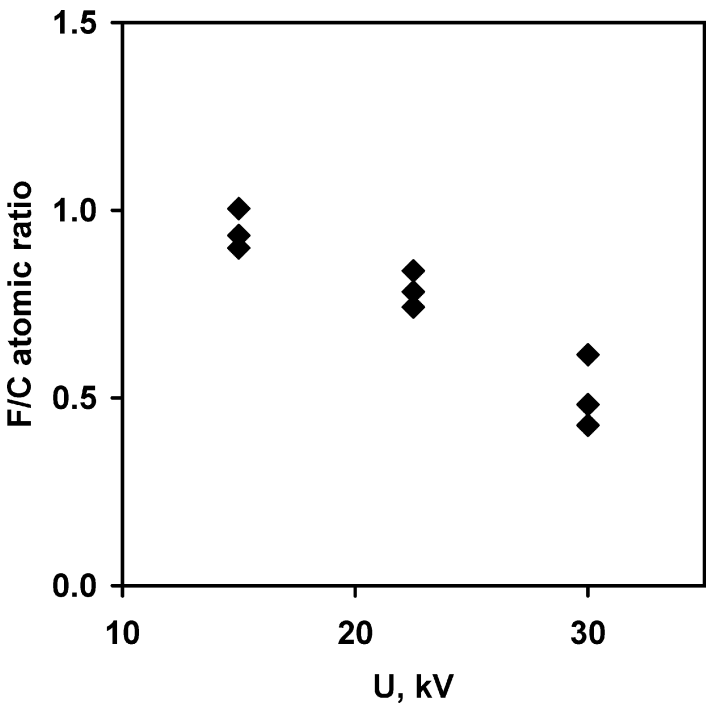

Figure 2: F/C atomic ratio vs. voltage.

immersion ion implantation (HPIII) treatment of the surface of UHMWPE induces amelioration in terms of the scratch resistance, temperature, mean surface roughness, oxygen content, and surface hardness, while the surface slope and elastic modulus often decreased, but it is possible to enhance these characteristics upon treatment. Low values of temperature and mean roughness favour the reduction of the surface slope [30]. In parallel, the nanomechanical, chemical and wear properties of the UHMWPE surface have been significantly enhanced following treatment with helium plasma immersion ion implantation (HePIII). Over the ranges of the parameters, the surface hardness increased by up to six times, whereas the loss in volume following multipass decreased by up to about 2.5 times [31].

In a related study, the influence of nitrogen plasma immersion ion implantation (NPIII) on the surface of UHMWPE was investigated as well. The results suggested a relative increase in surface hardness, macroscopic temperature and mean surface roughness, while the loss in volume decreased. However, the elastic modulus decreased or maybe even increased depending on the actual parameter set applied in the process. According to the parameter range studied, a reduction in wear rate is strongly dependent on thermal effects [32]. A statistical study by Tóth et al. [33] that revised the literature of engineering plastics treated by plasma-based ion implantation (PBII) and plasma-based ion implantation and deposition (PBIID) concluded that there is a rapidly trending in the number of related publications. As a consequence, the effect of nitrogen plasma-based ion implantation (NPBII) on poly(tetrafluoroethylene) (PTFE) was discovered by Kereszturi et al. [34]. The study observed that the F/C atomic ratio significantly decreased in an inverse relationship with the voltage as shown in Fig. 2. Meanwhile the surface roughness increased inversely with the voltage and correlated directly with fluence as shown in Fig. 3.

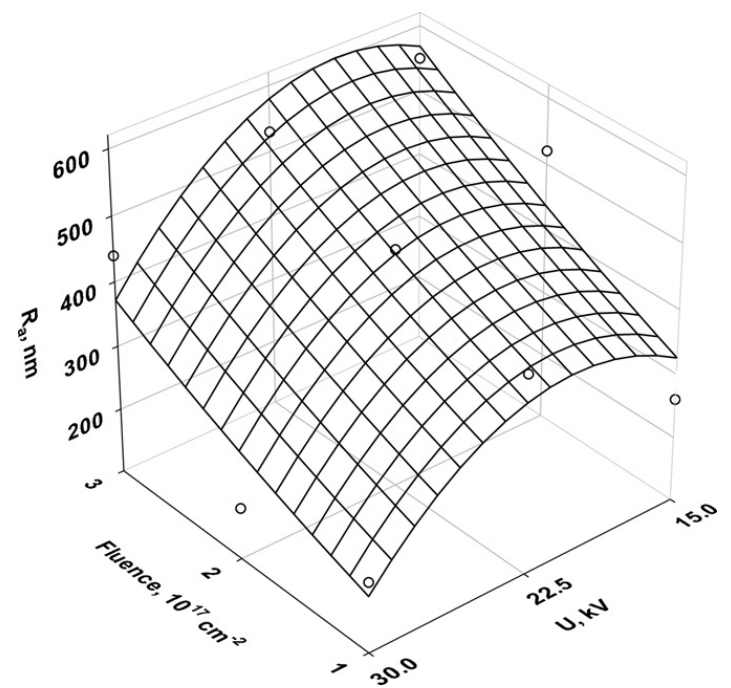

Figure 3: Mean surface roughness of PTFE vs. fluence and voltage.

Although a clear relationship between wear volume and the main process parameters was not observed, in general this was improved following treatment along with an increase in surface roughness and $\mathrm{O} / \mathrm{C}$ atomic ratio. Furthermore, the water contact angle recorded increased under low voltages and high fluences.

Atmospheric dielectric barrier discharge (DBD) plasmas enhance the wettability and surface roughness of polypropylene (PP) proportionally to an increase in the duration of plasma exposure [35]. Also, the surface roughness of PP increases linearly with the exposure time of atmospheric DBD plasma due to degradation of the polymer surface and the formation of nodulelike features. These nodules are shaped by highly oxidized short fragments of polymer which are referred to as low-molecular-weight oxidized materials (LMWOMs) in the literature [15]. In a subsequent study, Kostov et al. [36] reported that modifications in terms of the surface of different engineering plastics, such as polyethylene terephthalate (PET), polyethylene (PE) and PP could be achieved by atmospheric pressure plasma jets (APPJ). The primary aim of this research was to identify the optimal treatment conditions as well as compare the effect of APPJs on another source of atmospheric pressure plasmas, e.g., DBD on the characteristics of polymer surfaces. As a consequence of APPJ treatment the surface roughness is increased as shown in Fig. 4. However, nodule-like structures were produced as well, but were much smaller compared to those constituted in the previous study when the polymer was treated by DBD. This was attributed to the higher degree of polymer degradation during DBD treatment. The adhesion strength of PP and perfluoroalkoxy alkanes (PFAs) has been significantly enhanced due to atmospheric plasma treatment under several gas flows. The characteristics of the surface introduced hydrophilic functional groups where the level 


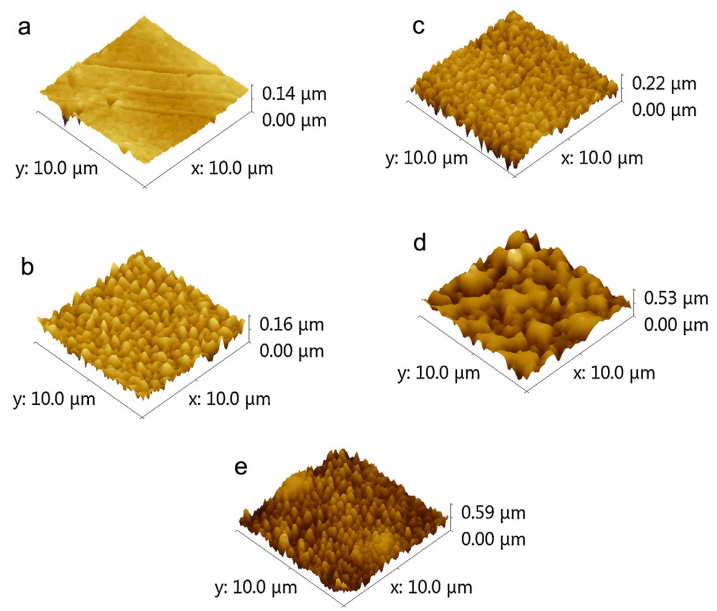

Figure 4: AFM images of PP (a) untreated; (b) $30 \mathrm{~s}$ treated; (c) $30 \mathrm{~s}$ treated and washed; (d) $60 \mathrm{~s}$ treated; (e) $60 \mathrm{~s}$ treated and washed. All treatments were conducted with sample reciprocations using a signal amplitude of 10 $\mathrm{kV}$, frequency of $37 \mathrm{kHz}$ and Ar flow of $1.3 \mathrm{l} / \mathrm{min}$.

of improvement changed in proportion to the duration of the treatment as illustrated in Fig. 5 [37]. Although atmospheric pressure glow (APG) discharge plasma treatment is moderate in terms of energy characteristics, APGderived fluoropolymers exhibit similar surface properties under conventional low-pressure plasmas [38]. Treating metals and polymers by a cold arc-plasma jet under atmospheric pressure leads to a superficial improvement in hydrophilicity and a decrease in the water contact angle of these materials as shown in Fig. 6 [39].

On the other hand, the literature shows that modifications to the surface of aromatic polymers by dielectric barrier discharge (DBD) can achieve a substantial degree of chemical functionalization on the polymer surface by applying relatively low or intermediate levels of power without suffering severe topographical damage [40]. The surface modification of a PET film by an atmosphericpressure plasma in combination with different gas flows promptly improved its hydrophilicity and was followed by hydrophobic recovery after longer durations [41]. In parallel, significant changes in the morphology and reactivity of PET surfaces have been observed $[42,43]$. When

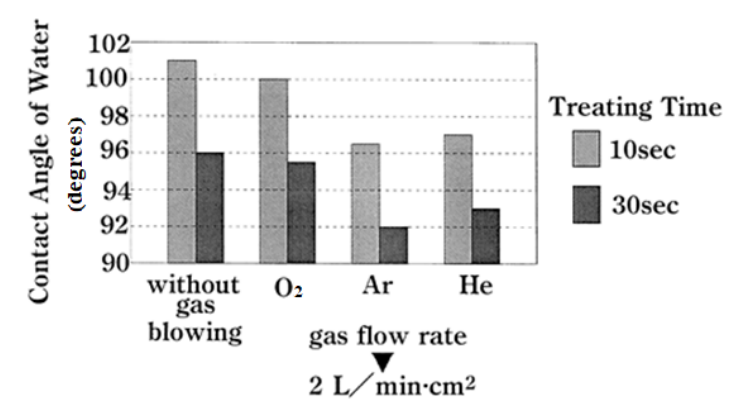

Figure 5: Effect of gas blowing on wettability of PFA film.

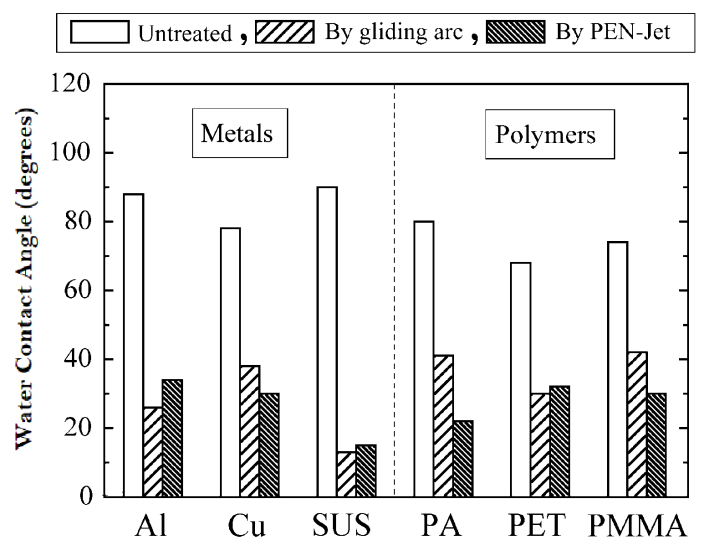

Figure 6: Water contact angles of various materials after treatment.

exposed to air the processing parameters, such as discharge power, processing speed, processing duration, and electrode configurations, affect the nature and scale of changes to the surface. In general, longer durations (low processing speed and a high number of cycles) and high levels of power induced greater changes in the surface wettability of the polymer [44].

Among the various environmental gases studied, air and oxygen yielded the highest levels of hydrophilicity, while argon and nitrogen resulted in lower degrees of hydrophilicity of the PET surface [45]. Cold atmosphericpressure plasmas (surface dielectric barrier discharge SDBD) improve the oxygen and nitrogen contents of PET [46]. In comparison to PET, the effects of plasma treatment on polyether ether ketone (PEEK) have been studied less frequently, but also lead to enhanced degrees of hydrophilicity and adhesion [47] due to the incorporation of functional groups and greater surface roughness following DBD [48]. The hydrophilicity, which is governed by the oxygenation of PEEK following DBD in the air, also recovered after several months through loss of the structurally related functional groups, but it remained more stable than other non-aromatic polymers [49]. Nylon 6 (PA6) exhibited a reduction in surface roughness, and an increase in the $\mathrm{O} / \mathrm{C}$ and N/C ratios due to diffuse coplanar surface barrier discharge (DCSBD) plasma treatment in two different gas flows (nitrogen and oxygen). However, the oxygen DCSBD plasma was more efficient in terms of modifying the surface compared to the nitrogen equivalent [16]. Also, plasma treatment enhances the contact angle and alters the surface topography of Nylon 66 (PA66) [50]. Plasma pre-treatment of the surface of the biopolymer Poly L Lactic Acid (PLLA) leads to the formation of pits in the crystalline phase accompanied by a mild increase in surface roughness [51]. 


\section{Tribology of Plasma-treated polymer surfaces}

\subsection{Friction of polymers}

Many studies have dealt with the tribology of polymers $[52,53]$. Hardness and the elastic modulus are governed by the penetration depth, maximum load and strain rate [54]. Microcuttings are a consequence of ploughing, and they may exacerbate the friction force under specific conditions. Friction that results from elastic hysteresis is known as the deformation component $[55,56]$. "The mechanical component results from the resistance of the softer material to "ploughing" by asperities of the harder one" [57]. The adhesive bonds generated between the surfaces in the frictional contact are referred to as the adhesion component. The adhesion component is higher than the deformation (mechanical) equivalent [58]. The friction force is equal to the sum of the adhesion and deformation components as shown in Eq. 1 [59]. From this, the reason for polymer transferred layers forming on the metal counterface during frictional contact can be determined. The transferred films are an essential factor which must be taken into consideration whilst estimating the tribological behaviour of polymers [53]. The effect of load, sliding velocity and temperature on friction are also important parameters that could influence the tribological behaviour of the polymer:

$$
F_{\mathrm{f}}=F_{\mathrm{a}}+F_{\mathrm{d}}[\mathrm{N}]
$$

where $F_{\mathrm{f}}$ represents the friction force, $F_{\mathrm{a}}$ the adhesion component, and $F_{\mathrm{d}}$ the deformation component of friction. Under low loads, $F_{\mathrm{f}} \approx F_{\mathrm{a}}$ since $F_{\mathrm{d}}$ is far smaller than $F_{\mathrm{a}}$.

\subsection{Wear of polymers}

Wear is the undesirable removal of layers from the surface of a material. Wear occurs when two materials come into contact as a result of movement. Mechanical stress, temperature and chemical reactions directly influence the characteristics of the surface layer. Polymers are sensitive to these factors due to their particular structure and mechanical behaviour. The interface temperature can be significantly higher than the temperature of the environment. The wear of some polymers, that were examined by Lancaster [60] whilst being slid against steel, was found to be influenced by temperature with regard to polymers that the pass is minimum at the characteristic temperature. The accurate classification with regard to the wear of a polymer is not a trivial matter due to the highly diverse nature of such mechanisms [53, 61, 62]. However, abrasion, adhesion and fatigue are the three most common types of polymer wear that occur during the sliding process.

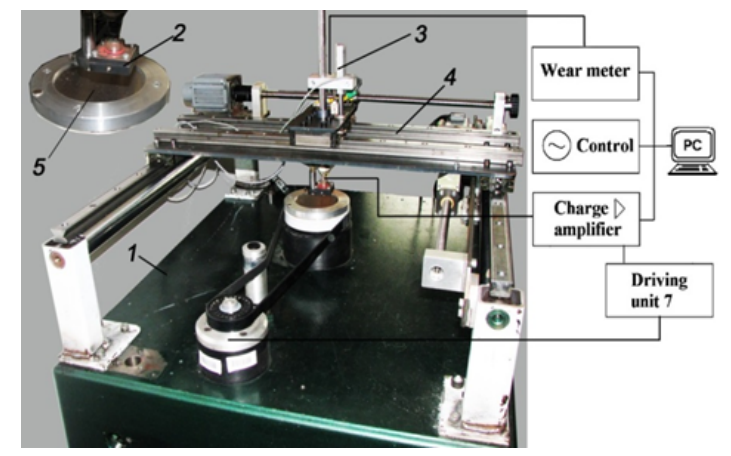

Figure 7: Pin-on-disc tribological test system : 1) base frame, 2) pin holder, 3) loading head, 4) positioning rail, 5) rotating steel disc.

\subsection{Tribological tests of polymers}

The tribological behaviour of a specific material is not inherent of its properties as far as strength, elastic modulus, etc., are concerned. The influence of friction and wear on the overall performance of a polymer is strongly dependent on the entire configuration of the test. To evaluate the polymer under operating conditions that occur in actual structures, test configurations have to simulate the main sliding mode as accurately as possible in terms of system pair materials, contact geometry, contact pressure, sliding motion, sliding velocity, environmental conditions, mechanical stiffness, etc. As a consequence, regular basis tribo-test systems are assembled from test apparatus that has yet to be standardized.

Several parameters should be taken into consideration to select the most favourable test system, i.e. the structure of the material (macro- or microstructure), contact conditions (whether the contacting bodies possess the same radii of curvature as in a pin-on-disc test or different radii of curvature as in the ball-on-disc test), and energy dissipation (sliding temperature) [63]. The real tribosystem of the elements of a polymer is considered to be the most dependable test, however, due to its expense and impractical nature the test cannot be conducted regularly.

The scale of tribological tests varies from 'field tests' that consist of 'large-scale simulation tests' on real components to 'laboratory tests' on artificial samples which are widespread in the field of the tribological research of polymers due to the small apparatus used and their relatively low cost and versatility with regard to the testing of various materials under different test conditions, e.g. pin-on-disc Fig. 7).

\subsection{Tribological behaviour of the surface of polymers treated by plasmas}

It is hard to accurately predict the effects of plasma surface treatment on the tribological behaviour of polymers, due to the multitude of mechanisms that govern such processes. It can be expected that functionalization, 

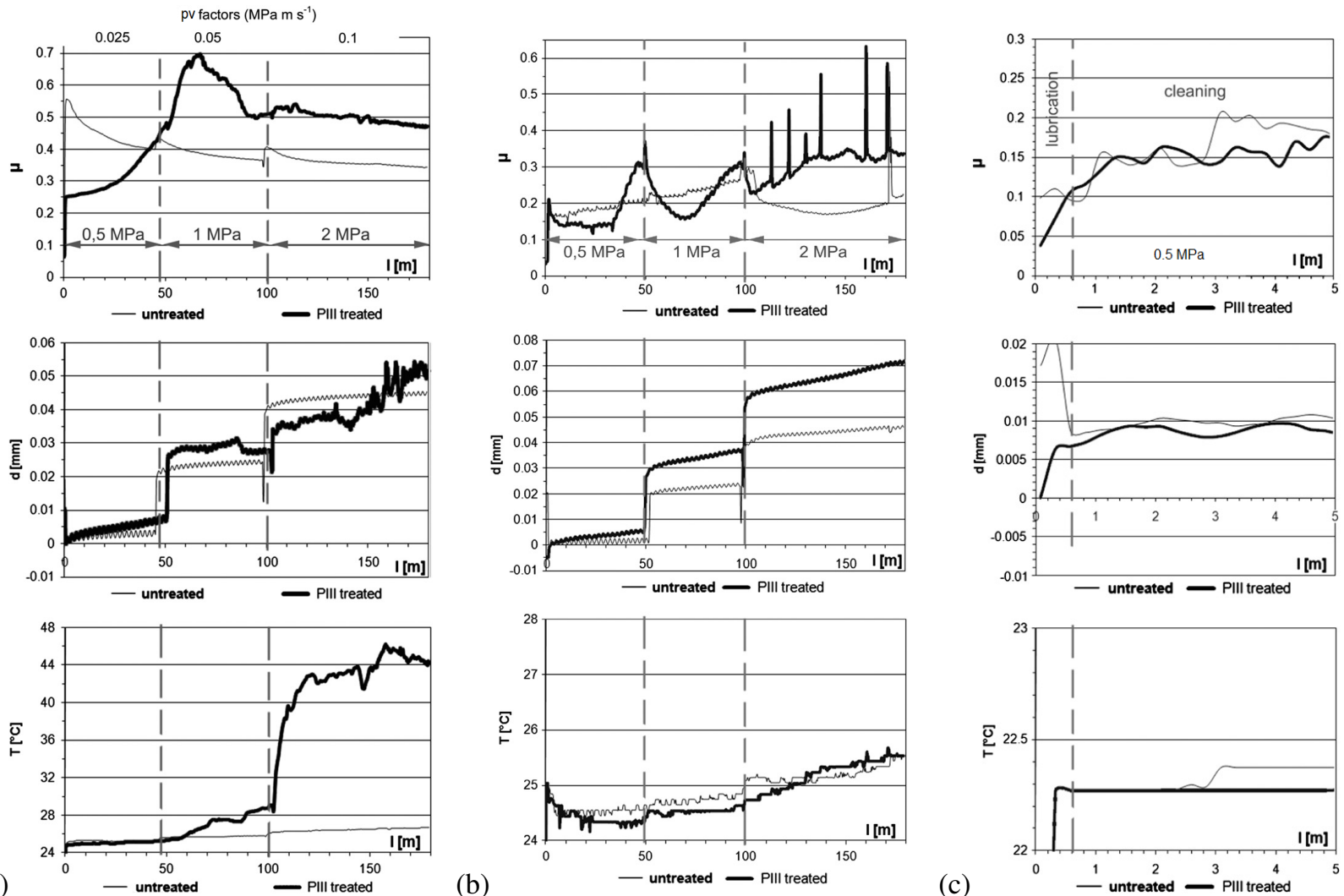

Figure 8: Tribological behaviour of pristine and NPIII-treated PA6; (a) dry conditions; (b) water lubrication conditions; and (c) run-out lubrication conditions.

crosslinking and chain scission will affect their chemical and mechanical surface properties after plasma treatment, which in turn will alter friction and wear characteristics. However, it cannot be confirmed whether such alterations lead to improved tribological properties or not, this can only be ascertained after the treated surface is tested.

The tribological behaviour of rubber treated by plasma has been thoroughly investigated, indicating improvements in terms of friction and wear resistance [13]. The pin-on-disc test yields the lower friction coefficient of PC and PP, whereas PE and PS exhibit larger coefficients of friction after atmospheric plasma treatment compared to their pristine surfaces. Bismarck et al. [64] attributed the significant decrease with regard to the friction coefficient of PC either to the most substantial reduction in contact angle or the changes in the chemical and simultaneously the physical properties of PC after treatment. On the other hand, the increase in the extent of crosslinking after atmospheric plasma treatment resulted in lower levels of friction and wear of PEEK composites [65], while argon plasma treatment led to a higher friction coefficient of PET [12].

The effects of Nitrogen plasma immersion ion implantation (NPIII) on PET indicated improvements with regard to scratch resistance [66]. Kalácska et al. [67] demonstrated that the benefits of sliding tribological properties are strongly dependent on the sliding condi- tions: a lower degree of friction and enhanced wear performance of PET treated by PIII only occurred in the presence of low $p v$ factors under dry or water-lubricated sliding conditions. Five minutes of atmospheric plasma treatment is sufficient to reduce the coefficient of friction and enhance the wear properties of a UHMW-PE film under a constant $p v$ factor [68]. In contrast, UHMW-PE treated by atmospheric pressure gas plasma does not exhibit a significant change in terms of wear properties after a treatment time of two minutes.

Since the level of wear reduced by half after longer treatment times, the duration a polymer is exposed to a plasma plays a major role with regard to the tribological properties of the treated surface, in particular for UHMWPE [69]. UHMW-PE treated by a cold argon plasma using dielectric barrier discharge (DBD) supports such a finding since (under dry conditions) an increase in the friction coefficient with treatment time was observed whereas the wear volume reduced over the treatment time due to modifications of its surface. Under normal saline ( $\mathrm{N}$-saline) lubrication conditions, wear volume and friction were reduced over the treatment time which is indicative of an increase in surface wettability and, therefore, enhanced surface lubrication capability [70]. Sagbas [71] reported an increase in friction and improvement in the wear properties of conventional UHMW-PE after plasma treatment, whereas the friction coefficient was unaffected in terms of 


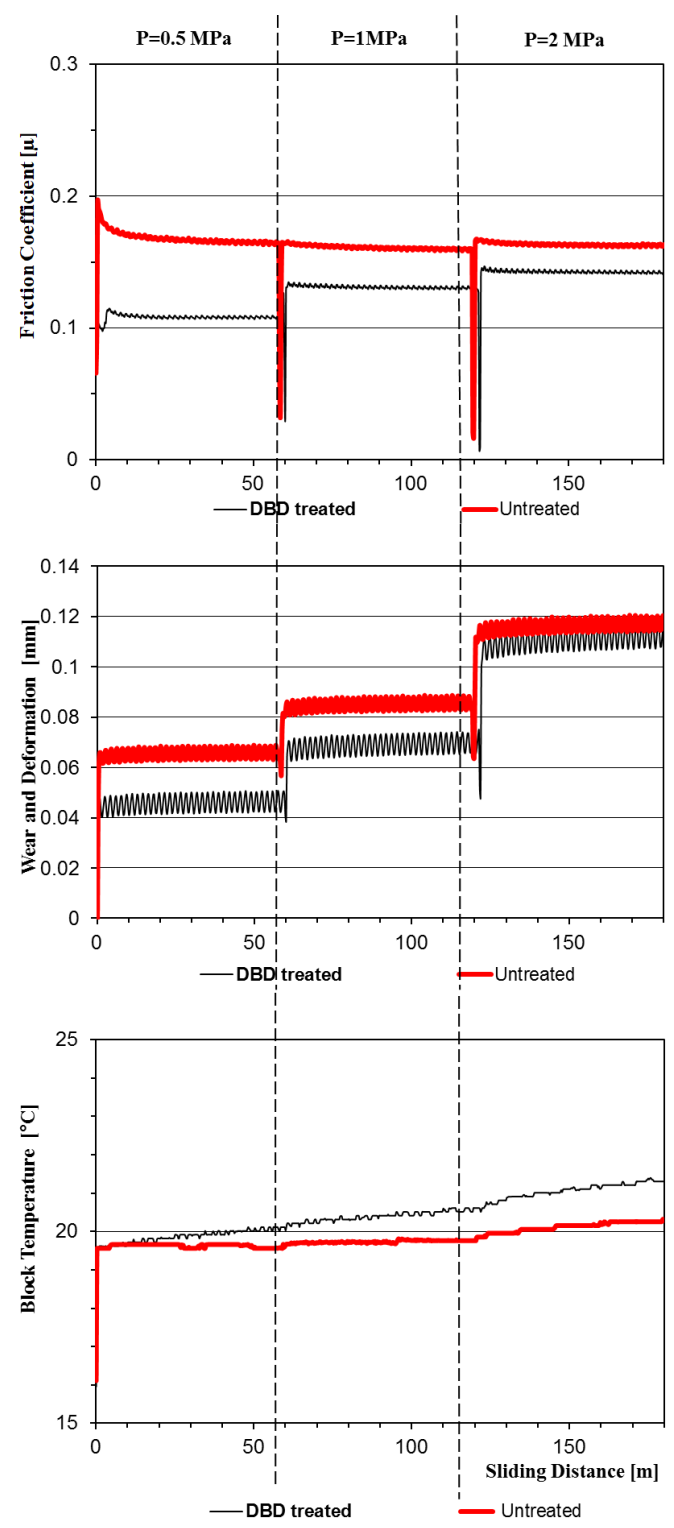

Figure 9: Tribological testing under dry sliding conditions at 0.5 ; 1 ; and $2 \mathrm{MPa}$; including online measurements of coefficients of friction, (specific wear and displacement $\Delta h)$, and temperature.

vitamin-E-blended UHMW-PE under the same test conditions. However, the wear factor slightly decreased compared to the significant improvement with regard to the wear properties of conventional UHMW-PE as a consequence of the highly cross-linked nature of conventional UHMW-PE.

According to the brief review above with regard to the effect of some plasmas on different polymers, the ability of plasmas to alter the surface characterization and thereby the tribological behaviour of polymers is unquestionable. However, the tribological behaviour of the treated surface depends on several factors such as the type of plasma, treatment method, exposure time, operating mechanism and lubrication conditions amongst many other factors. Kalácska et al. [72] studied the tribological behaviour of PA6 treated by nitrogen plasma immersion ion implantation (NPIII) under different conditions (dry, water and oil lubrication) and various pressure velocity factors $(p v)$. The results show that the friction coefficient and specific wear of treated PA6 are lower than that of the untreated one under dry sliding conditions and low $p v$ factors, while the friction coefficient, specific wear and contact temperature of treated PA6 are higher than the pristine equivalent under high $p v$ factors (Fig. 8a).

On the other hand, the water lubricant reduces the adhesive component of friction after treatment, which was reflected in the fluctuation of the friction behaviour of the treated surface (Fig. 8b). However, under continuous oil lubrication, no difference could be detected between the treated and untreated parameters, therefore, the run-out type was preferred in terms of detecting such a difference. Test conditions in terms of run-out oil lubrication exhibit a lower friction coefficient for treated PA6 than the pristine equivalent in the presence of low $p v$ factors as a consequence of an increase in the dispersive component (Fig. 8c).

In contrast, our last work [73] elaborated on the effect of atmospheric DBD plasma on the tribological behaviour of PET under various test conditions ( 3 "dry" normal load and "run-out lubrication" constant normal load conditions). The effect of DBD plasma treatment on the characterization of the surface was interpreted as an enhancement of the surface energy and reduction in the surface roughness due to the melting of surface asperities. However, increasing the surface wettability induces higher coefficients of friction according to Archard's theory of friction [74]. The dry tribological test yielded unexpected behaviour where the coefficient of friction of the treated surface was lower than the pristine equivalent under different $p v$ factors. Also, the specific wear and the vertical deformation were enhanced. However, the interface temperature of the treated surface was higher than the untreated one (Fig. 9). The reduction in the coefficient of friction can be theoretically attributed to the smaller contributions of a deformation component. In a related context, a "run-out" oil lubrication test yielded a lower coefficient of friction for the treated surface due to a rise in the surface energy after treatment, leading to a favourable enhancement with regard to the adsorption of the lubricant as shown in Fig. 10. By using the analysis and comparison of the previously reviewed studies, it can be said that atmospheric DBD plasma can be an effective technique nowadays for the treatment of polymer surfaces that aims to reduce friction and improve wear under dry and run-out lubrication conditions under various $p v$ factors, especially under lower ones compared to other techniques, e.g. NPIII.

\section{Conclusion}

In conclusion, the reviewed research and results have apparently shown the capability of plasmas to modify the 


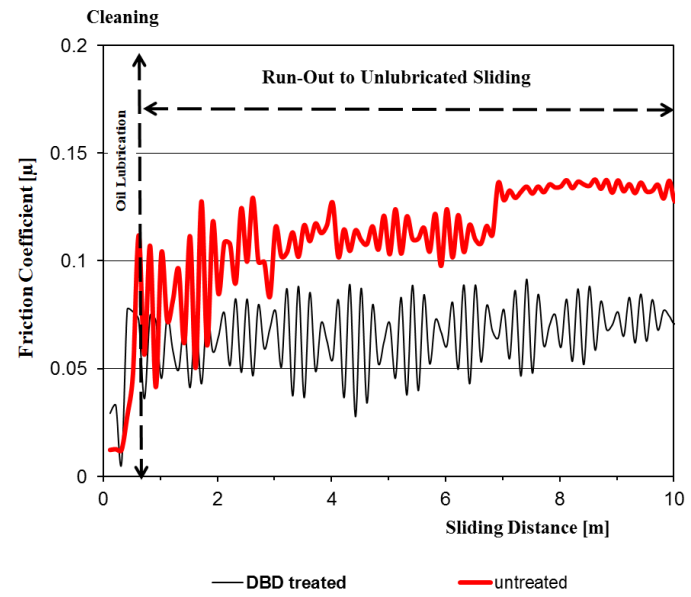

Figure 10: Tribological testing under lubricated sliding and "run-out" conditions at $0.5 \mathrm{MPa}$.

surfaces of polymers which results in a change in the tribological properties of surfaces. However, the effect of plasmas depends on several factors such as the sources of plasmas, vacuum, temperature, pressure, etc. The essential points concerning the tribological behaviour of polymers that are subjected to plasma treatment are summarized below:

- Plasmas can efficiently alter the characterization of polymer surfaces by utilizing different sources such as APPJ, PIII, APG, PBII and DBD and various vacuums which results in the enhancement of surface wettability and an increase in surface roughness with few exceptions. Atmospheric DBD plasma can achieve the optimum surface configuration in a shorter time.

- There is a paucity of studies which deal with the tribological behaviour of polymers in terms of plasma treatment. Most studies focused on the effect of plasmas on the tribology of engineering polymers especially PET, PA6, and in some cases PEEK. However, no studies appear to deal with Polyolefins, except some studies which investigate the tribology of UHMW-PE for medical applications in particular.

- UHMW-PE exhibits a higher coefficient of friction and improvements in specific wear after plasma treatment under dry conditions where cross-linking plays a prominent role in terms of controlling the wear rate upon plasma treatment. However, the lubricated tribological test of UHMW-PE resulted in a lower coefficient of friction due to an increase in wettability.

- The comparative investigation of engineering polymers treated by different plasmas under the same conditions (PA6 treated by NPIII and PET treated by atmospheric DBD) can explain the remarkable effect of atmospheric DBD plasma on the tribological behaviour of PET under dry conditions where the friction coefficient of PET remained lower than the pristine equivalent, whilst subjected to different $p v$ factors. In contrast, PA6 can only sustain low $p v$ factors if a low coefficient of friction is desired in the case of NPIII treatment.

- With regard to the aforementioned comparative investigation, atmospheric DBD plasma yielded a unique reduction in the friction coefficient of PET throughout the duration of the test under "run-out" oil lubrication conditions. On the other hand, a slight reduction in the friction coefficient was recorded when PA6 was treated by NPIII under the same test conditions.

\section{REFERENCES}

[1] Field, J.: David Tabor. 23 October 1913-1926 November 2005, Biographical Memoirs of Fellows of the Royal Society, 2008 DOI: 10.1098/rsbm.2007.0031

[2] Jost, P.: Interview with Luminary Professor H. Peter Jost - The Man Who Gave Birth to the Word "Tribology". (N. C. Jim Fitch, Interviewer), online at: Machinerylubrication.com, accessed on 201705-24

[3] Mitchell, L. (2012). The Fiction of Nonfriction, Ward, J. ed. Popular Science, 2012 281(5), 40

[4] Wikipedia: Tribology, online at: https://en.wikipedia.org/wiki/Tribology\#cite_note1, accessed on 2017-10-24

[5] Myshkin, N.K.; Petrokovets, M.I.; Kovalev, A.V.: Tribology of polymers: adhesion, friction, wear, and mass-transfer, Tribology International, 2005 38(1112), 910-921 DOI: 10.1016/j.triboint.2005.07.016

[6] Briscoe, B.J.: Interfacial Friction of Polymer Composites: General Fundamental Principles, Composite Materials Series, 1986 1, 25-59 DOI: 10.1016/B9780-444-42524-9.50006-5

[7] Singer, I.L.; Pollock, H. (Eds.): Fundamentals of friction: macroscopic and microscopic processes (Kluwer Academic Publisher, London) 1992 ISBN: 978-94-011-2811-7

[8] Akram, M.; Jansen, K.M.B.; Ernst, L.J.; Bhowmik, S.: Atmospheric plasma modification of polyimide sheet for joining to titanium with high temperature adhesive, International Journal of Adhesion and Adhesives, 2016 65, 63-69 DOI: 10.1016/j.ijadhadh.2015.11.005

[9] Petrie, E.M.: Handbook of Adhesives and Sealants, Second Edition (McGraw-Hill Companies, Inc., New York) 2007 ISBN: 9780071479165

[10] Noeske, M.; Degenhardt, J.; Strudthoff, S.; Lommatzsch, U.: Plasma jet treatment of five polymers at atmospheric pressure: surface modifications and the relevance for adhesion, International Journal of Adhesion and Adhesives, 2004 24(2), 171-177 DOI: 10.1016/j.ijadhadh.2003.09.006 
[11] Rotheiser, J.: Joining of Plastics, 3rd Edition (Carl Hanser Verlag GmbH \& Co. KG, Cincinnati) 1998 ISBN: 978-1-56990-445-9

[12] Leggett, G.J.; Beake, B.D.: Development of surface morphology, local friction, and adhesion in plasma treated poly (ethylene terephthalate) films, Polymer Preprints(USA), 1998 39(2), 1228-1229

[13] Segu, D.Z.: NBR surface modification by Ar plasma and its tribological properties, Industrial Lubrication and Tribology, 2016 68(2), 227-232 DOI: 10.1108/ILT-05-2015-0062

[14] Kostov, K.G.; Hamia, Y.A.A.; Mota, R.P.; Dos Santos, A.L.R.; Nascente, P.A.P.: Treatment of polycarbonate by dielectric barrier discharge (DBD) at atmospheric pressure, Journal of Physics: Conference Series, 2014 511(1), 012075. IOP Publishing DOI: 10.1088/1742-6596/511/1/012075

[15] Kostov, K.G.; Nishime, T.M.C.; Hein, L.R.O.; Toth, A.: Study of polypropylene surface modification by air dielectric barrier discharge operated at two different frequencies, Surface and Coatings Technology, 2013 234, 60-66 DOI: 10.1016/j.surfcoat.2012.09.041

[16] Novák, I.; Popelka, A.; Valentín, M.; Chodák, I.; Špírková, M.; Tóth, A.; Kleinová, A.; Sedliačik, J.; Lehock $\imath$, M.; Marônek, M.: Surface behavior of polyamide 6 modified by barrier plasma in oxygen and nitrogen, International Journal of Polymer Analysis and Characterization, 2014 19(1), 31-38 DOI: 10.1080/1023666X.2014.850907

[17] Károly, Z.; Klébert, S.; Al-Maliki, H.; Pataki, T.: Comparison of NPIII and DBD Plasma Treatment in Terms of Wettability of PTFE and PA6, Scientific Bulletin Series C: Fascicle Mechanics, Tribology, Machine Manufacturing Technology, 2016 30, 47

[18] Al-Maliki, H.; Zoltán, Sz.; Róbert, K.; Kalácska, G.: Shear strength of polypropylene bonded joints using pristine and DBD plasma treated surfaces, Mechanical Engineering Letters R\&D, SZIE, 2016 14, 71-77

[19] Al-Maliki, H.; Kalácska, G.: The effect of atmospheric DBD plasma on surface energy and shear strength of adhesively bonded polymer, Hungarian Agricultural Engineering, 2017 31, 52-58 DOI: 10.17676/HAE.2017.31.52

[20] Ionita, M.D.; Teodorescu, M.; Stancu, C.; Stancu, E.C.; Ionita, E.R.; Moldovan, A.; Acsente, T.; Bazavan, M.; Dinescu, G.: Surface modification of polymers at atmospheric pressure in expanding RF plasmas generated by planar dielectric barrier discharges, Journal of Optoelectronics and Advanced Materials, 2010 12(3), 777-782

[21] Nastuta, A.V.; Rusu, G.B.; Topala, I.; Chiper, A.S.; Popa, G.: Surface modifications of polymer induced by atmospheric DBD plasma in different configurations, Journal of Optoelectronics and Advanced Materials, 2008 10(8), 2038-2042
[22] Hergelová, B.; Homola, T.; Zahoranová, A.; Plecenik, T.; Kováëik, D.: Plasma surface modification of biocompatible polymers using atmospheric pressure dielectric barrier discharge, WDS'12 Proceedings of Contributed Papers, Part II, pp. 128133, 2012 ISBN: 978-80-7378-225-2

[23] Tendero, C.; Tixier, C.; Tristant, P.; Desmaison, J.; Leprince, P.: Atmospheric pressure plasmas: A review, Spectrochimica Acta Part B: Atomic Spectroscopy, 2006 61(1), 2-30 DOI: 10.1016/j.sab.2005.10.003

[24] Chapman, B.: Glow Discharge Processes (Wiley, New York) 1980 ISBN: 978-04-7107-828-9

[25] Lieberman, M.A.; Lichtenberg, A.J.: Principles of plasma discharges and materials processing, MRS Bulletin, 1994 30, 899-901 DOI: https://doi.org/10.1557/mrs2005.242

[26] Conrads, H.; Schmidt, M.: Plasma generation and plasma sources, Plasma Sources Science and Technology, 2000 9(4), 441 IOP Publishing

[27] Kalácska, G.; Károly, Z.; Klébert, S.; András, E.: NPIII Treatment towards to Cold Atmospheric Plasma as Surface Modification Technics of Engineering Polymers, Scientific Bulletin Series C: Fascicle Mechanics, Tribology, Machine Manufacturing Technology, 2015 29, 51

[28] Boulos, M.I.; Fauchais, P.; Pfender, E.: Thermal plasmas: fundamentals and applications (Springer Science \& Business Media, New York) 2013

[29] Tóth, A.; Bertóti, I.; Szilágyi, E.; Dong, H.; Bell, T.; Juhász, A.; Nagy, P.M.: Surface characterization of ultrahigh molecular weight polyethylene after nitrogen ion implantation, Surface and Interface Analysis, 2000 30(1), 434-438 DOI: 10.1002/10969918(200008)30:1<434::AID-SIA788>3.0.CO;2-W

[30] Tóth, A.; Mohai, M.; Ujvári, T.; Bertóti, I.: Hydrogen plasma immersion ion implantation of ultrahigh molecular weight polyethylene, Surface and Interface Analysis, 2006 38(4), 898-902 DOI: 10.1002/sia.2197

[31] Tóth, A.; Mohai, M.; Ujvári, T.; Bertóti, I.: Advanced surface modification of ultrahigh molecular weight poly (ethylene) by helium plasma immersion ion implantation, Polymers for Advanced Technologies, 2006 17(1112), 898-901 DOI: 10.1002/pat.788

[32] Tóth, A.; Bertóti, I.; Mohai, M.; Ujvári, T.: Surface modification of polyethylene by nitrogen PIII: Surface chemical and nanomechanical properties, Materials Science Forum, 2007 537, 255-262 DOI: 10.4028/www.scientific.net/MSF.537-538.255

[33] Tóth, A.; Kereszturi, K.; Mohai, M.; Bertóti, I.: Plasma based ion implantation of engineering polymers, Surface and Coatings Technology, 2010 204(18), 2898-2908 DOI: 10.1016/j.surfcoat.2009.12.004

[34] Kereszturi, K.; Tóth, A.; Mohai, M.; Bertóti, I.; Szépvölgyi, J.: Nitrogen plasma-based ion implantation of poly (tetrafluoroethylene): Effect of the main parameters on the surface properties, Applied 
Surface Science, 2010 256(21), 6385-6389 DOI: 10.1016/j.apsusc.2010.04.021

[35] Nishime, T.M.C.; Tóth, A.; Hein, L.R.O.; Kostov, K.G.: Surface characteristics analysis of polypropylene treated by dielectric barrier discharge at atmospheric pressure, Journal of Physics: Conference Series, 2012 370(1), 012025 IOP Publishing DOI: 10.1088/1742-6596/370/1/012025

[36] Kostov, K.G.; Nishime, T.M.C.; Castro, A.H.R.; Tóth, A.; Hein, L.R.D.O.: Surface modification of polymeric materials by cold atmospheric plasma jet, Applied Surface Science, 2014 314, 367-375 DOI: 10.1016/j.apsusc.2014.07.009

[37] Tsuchiya, Y.; Akutu, K.; Iwata, A.: Surface modification of polymeric materials by atmospheric plasma treatment, Progress in Organic Coatings, 1998 34(1), 100-107 DOI: 10.1016/S0300-9440(97)001173

[38] Prat, R.; Koh, Y.J.; Babukutty, Y.; Kogoma, M.; Okazaki, S.; Kodama, M.: Polymer deposition using atmospheric pressure plasma glow (APG) discharge, Polymer, 2000 41(20), 7355-7360 DOI: 10.1016/S0032-3861(00)00103-8

[39] Toshifuji, J.; Katsumata, T.; Takikawa, H.; Sakakibara, T.; Shimizu, I.: Cold arc-plasma jet under atmospheric pressure for surface modification, Surface and Coatings Technology, 2003 171(1), 302306 DOI: 10.1016/S0257-8972(03)00290-1

[40] Upadhyay, D.J.; Cui, N.Y.; Meenan, B.J.; Brown, N.M.D.: The effect of dielectric barrier discharge configuration on the surface modification of aromatic polymers, Journal of Physics D: Applied Physics, 2005 38(6), 922 IOP Publishing DOI: 10.1088/0022-3727/38/6/022

[41] Gotoh, K.; Kobayashi, Y.; Yasukawa, A.; Ishigami, Y.: Surface modification of PET films by atmospheric pressure plasma exposure with three reactive gas sources, Colloid and Polymer Science, 2012 290(11), 1005-1014 DOI: 10.1007/s00396-012-2600-7

[42] Esena, P.; Riccardi, C.; Zanini, S.; Tontini, M.; Poletti, G.; Orsini, F.: Surface modification of PET film by a DBD device at atmospheric pressure, Surface and Coatings Technology, 2005 200(1), 664667 DOI: 10.1016/j.surfcoat.2005.02.188

[43] Rashed, U.M.; Ahmed, H.; Al-Halwagy, A.; Garamoon, A.A.: Surface characteristics and printing properties of PET fabric treated by atmospheric dielectric barrier discharge plasma, The European Physical Journal-Applied Physics, 2009 45(1), pp.11001-p1-11001-p5 DOI: 10.1051/epjap:2008197

[44] Liu, C.; Brown, N.M.; Meenan, B.J.: Uniformity analysis of dielectric barrier discharge (DBD) processed polyethylene terephthalate (PET) surface, Applied Surface Science, 2006 252(6), 2297-2310 DOI: 10.1016/j.apsusc.2005.04.016

[45] Onsuratoom, S.; Rujiravanit, R.; Sreethawong, T.; Tokura, S.; Chavadej, S.: Silver loading on DBD plasma-modified woven PET surface for antimicrobial property improvement, Plasma Chemistry and Plasma Processing, 2010 30(1), 191-206 DOI: 10.1007/s11090-009-9199-6

[46] Novák, I.; Popelka, A.; Luyt, A.S.; Chehimi, M.M.; Špírková, M.; Janigová, I.; Kleinováa, A.; Stopkaf, P.; Šloufe, M.; Vankog, V.; Chodá, I.; Valentin, M.: Adhesive properties of polyester treated by cold plasma in oxygen and nitrogen atmospheres, Surface and Coatings Technology, 2013 235, 407-416 DOI: 10.1016/j.surfcoat.2013.07.057

[47] Zhang, S.; Awaja, F.; James, N.; McKenzie, D.R.; Ruys, A.J.: A comparison of the strength of autohesion of plasma treated amorphous and semi-crystalline PEEK films, Polymers for Advanced Technologies, 2011 22(12), 2496-2502 DOI: 10.1002/pat.1791

[48] Luo, H.; Xiong, G.; Ren, K.; Raman, S.R.; Liu, Z.; Li, Q.; Ma, C.; Li, D.; Wan, Y.: Air DBD plasma treatment on three-dimensional braided carbon fiber-reinforced PEEK composites for enhancement of in vitro bioactivity, Surface and Coatings Technology, 2014 242, 1-7 DOI: 10.1016/j.surfcoat.2013.12.069

[49] Upadhyay, D.J.; Cui, N.Y.; Anderson, C.A.; Brown, N.M.D.: Surface recovery and degradation of air dielectric barrier discharge processed poly (methyl methacrylate) and poly (ether ether ketone) films, Polymer Degradation and Stability, 2005 87(1), 3341 DOI: 10.1016/j.polymdegradstab.2004.07.006

[50] Labay, C.P.; Canal Arias, J.M.; Navarro Sentanyes, A.; Canal Barnils, C.: Comparison of the effects of corona and low pressure plasma on the release of caffeine from PA66 filaments, 51st Dornbirn Manmade Fibers Congress Lectures CD, pp. 1-6, 2012

[51] Slepička, P.; Michaljaničová, I.; Švorčík, V.: Controlled biopolymer roughness induced by plasma and excimer laser treatment, Express Polymer Letters, 2013 7(11), 950-958 DOI: 10.3144/expresspolymlett.2013.92

[52] Kragelskii, I.V.: Friction and Wear (Pergamon Press, Elmsford) 1982 ISBN: 978-00-8027-591-8

[53] Kovalev, N.K.; Myshkin, A.V.: Adhesion and friction of polymers, in: Polymer Tribology, Eds.: Sujeet, K.S.; Briscoe, B.J. (Imperial College Press, Singapore) 2009 DOI: 10.1142/9781848162044_0001

[54] Kovalev, A.; Shulha, H.; Lemieux, M.; Myshkin, N.; Tsukruk, V.V.: Nanomechanical probing of layered nanoscale polymer films with atomic force microscopy, Journal of Materials Research, 2004 19(3), 716-728 DOI: 10.1557/jmr.2004.19.3.716

[55] Bowden, F.P.; Tabor, D.: Friction and lubrication of solids (Clarendon Press, Oxford) 1964 ISBN: 019851204X

[56] Moore, D.F.: The Friction and Lubrication of Elastomers (Pergamon Press, Oxford) 1972 ISBN: 978-008016-749-7 
[57] Yamaguchi, Y.: Tribology of plastic materials (Elsevier, Tokyo) 1990 ISBN: 978-00-8087-580-4

[58] Bely, V.A.; Sviridenok, A.I.; Petrokovets, M.I.; Savkin, V.G.: Friction and Wear in Polymer-Based Materials (Pergamon Press, Oxford) 1982

[59] Kalácska, G.: An engineering approach to dry friction behaviour of numerous engineering plastics with respect to the mechanical properties, Express Polymer Letters, 2013 7(2), 199-210 DOI: 10.3144/expresspolymlett.2013.18

[60] Lancaster, J.K.: Relationships between the wear of polymers and their mechanical properties, Proceedings of the Institution of Mechanical Engineers, Conference Proceedings, 1968 183(16), 98-106

[61] Myshkin, N.K.; Kim, C.K.; Petrokovets, M.I.: Introduction to tribology (Chong Moon Gak, Seoul) 1997

[62] Blau, P.: Friction and wear transitions of materials (Noyes Publication, New York) 1989 ISBN: 978-081551-196-0

[63] Samyn, P.; Schoukens, G.; Quintelier, J.: Scaling Effects in Tribotesting of Polymers, in: Polymer Tribology, Eds.: Sujeet, K.S.; Briscoe, B.J. (Imperial College Press, Singapore) 2009 DOI: 10.1142/9781848162044_0003

[64] Bismarck, A.; Brostow, W.; Chiu, R.; Hagg Lobland, H.E.; Ho, K.K.: Effects of surface plasma treatment on tribology of thermoplastic polymers, Polymer Engineering \& Science, 2008 48(10), 1971-1976 DOI: 10.1002/pen.21103

[65] Zhang, R.; Häger, A.M.; Friedrich, K.; Song, Q.; Dong, Q.: Study on tribological behaviour of plasma-treated PEEK and its composites, Wear, 1995 181, 613-623 DOI: 10.1016/0043-1648(95)90177-9

[66] Kereszturi, K.; Tóth, A.; Mohai, M.; Bertóti, I.: Surface chemical and nanomechanical alterations in plasma immersion ion implanted PET, Surface and Interface Analysis, 2008 40(34), 664-667 DOI: 10.1002/sia.2643
[67] Kalácska, G.; Zsidai, L.; Kereszturi, K.; Mohai, M.; Tóth, A.: Sliding tribological properties of untreated and PIII-treated PETP, Applied Surface Science, 2009 255(11), 5847-5850 DOI: 10.1016/j.apsusc.2009.01.017

[68] Samad, M.A.; Satyanarayana, N.; Sinha, S.K.: Tribology of UHMWPE film on air-plasma treated tool steel and the effect of PFPE overcoat, Surface and Coatings Technology, 2010 204(9), 1330-1338 DOI: 10.1016/j.surfcoat.2009.09.011

[69] Perni, S.; Kong, M.G.; Prokopovich, P.: Cold atmospheric pressure gas plasma enhances the wear performance of ultra-high molecular weight polyethylene, Acta Biomaterialia, 2012 8(3), 1357-1365 DOI: 10.1016/j.actbio.2011.12.007

[70] Naresh, K.N.; Yap, S.L.; Khan, M.Z.; Pattela, S.R.S.: Effect of Argon Plasma Treatment on Tribological Properties of UHMWPE/MWCNT Nanocomposites, Polymers, 2016 8(8), 295 DOI: 10.3390/polym8080295

[71] Sagbas, B.: Effect of argon plasma surface modification on tribological behavior of biopolymers, Industrial Lubrication and Tribology, 2016 68(4), 508-514 DOI: 10.1108/ILT-11-2015-0176

[72] Kalácska, G.; Zsidai, L.; Keresztes, R.; Tóth, A.; Mohai, M.; Szépvölgyi, J.: Effect of nitrogen plasma immersion ion implantation of polyamide- 6 on its sliding properties against steel surface, Wear, 2012 290, 66-73 DOI: 10.1016/j.wear.2012.05.011

[73] AlMaliki, H.; Zsidai, L.; Samyn, P.; Szakál, Z.; Keresztes, R.; Kalácska, G.: Effects of atmospheric plasma treatment on adhesion and tribology of aromatic thermoplastic polymers, Polymer Engineering \& Science,(Early View) DOI: 10.1002/pen.24689

[74] Archard, J.: Contact and rubbing of flat surfaces, Journal of Applied Physics, 1953 24(8), 981-988 DOI: $10.1063 / 1.1721448$ 